\title{
'|||||||||||||||||||||||||||||||||||||||||||||||||||||||||||||||||||.
}

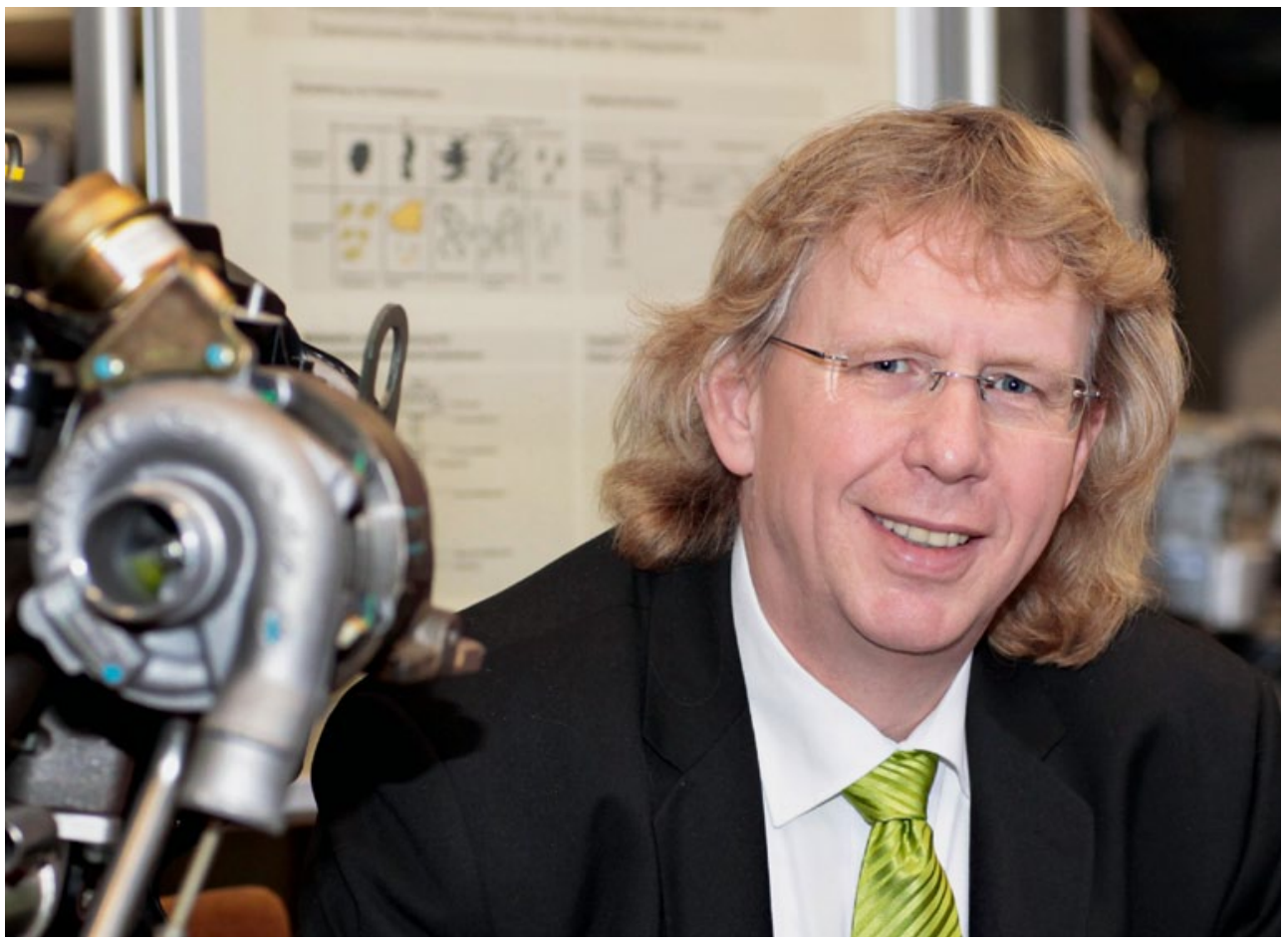

PROF. DR.-ING.

HERMANN ROTTENGRUBER

Leiter des Instituts für Mobile

Systeme, Otto-von-Guericke-

Universität Magdeburg

\section{EIN LOHNENDER ANSATZ?}

Durch die im letzten Jahrzehnt bei Ottomotoren in Breite eingeführte Benzin-Direkteinspritzung (BDE) konnten, insbesondere für Fahrzeuganwendungen, erhebliche Verbrauchsvorteile erzielt werden. Mithilfe der direkten Kraftstoffeinbringung wurden zum einen verbrauchsgünstige Arbeitsverfahren wie die Schichtladung erst ermöglicht. Zum anderen stellt die Direkteinspritzung in Kombination mit Turboaufladung, mit den breit auf dem Markt ausgerollten homogenen Downsizingkonzepten, die schärfste Waffe der Ottomotorenentwickler im Kampf gegen hohe $\mathrm{CO}_{2}$-Emissionen in den Fahrzeugflotten dar. Allerdings zeichnet sich im Zuge verschärfter Emissionsbestimmungen für Partikel- und Off-Cycle-Emissionen sowie der Notwendigkeit, den Verbrauch von Fahrzeugantrieben stärker zu reduzieren, ein dringender Weiterentwicklungsbedarf ab. Dabei stellt sich nun immer deutlicher die Frage, ob rein evolutionäre Schritte auch in der Weiterentwicklung von Einspritzsystemen ausreichen.

Derzeit stellen magnetisch betätigte Mehrlochventile für Homogenanwendungen und piezo-elektrisch angetriebene, nach außen öffnende Ventile mit Kegelstrahl für geschichtete Brennverfahren, jeweils mit einem maximalen Systemdruck von 200 bar, den im Serieneinsatz abgesicherten Stand der Technik dar. Im Besonderen kommt aber zur Beherrschung sich abzeichnender Emissionsanforderungen und immer weiter ansteigender Leistungsdichten die Fragestellung auf, ob und wieweit eine Anhebung des Einspritzdrucks für BDE-Systeme funktional sinnvoll und in wirtschaftlicher Hinsicht lohnend ist. Für die weitere Absenkung der Schadstoffemissionen ist grundsätzlich eine verbesserte Aufbereitung des KraftstoffLuft-Gemischs wünschenswert. Ein höherer Systemdruck erlaubt auch mit einer dementsprechend ertüchtigten Hardware weiter ausgefeilte Einspritzstrategien, die dann auch zur Unterdrückung von Vorentflammungsphänomenen und den gefürchteten „Superklopfern“ einsetzbar sind. Ungleich den Erfahrungen, die bei der Einspritzdruckanhebung bei dieselmotorischen Anwendungen gemacht wurden, zeichnen sich aufgrund bisher veröffentlichter Ergebnisse für die ottomotorische Anwendung gänzlich andersartige Mechanismen ab. Aufgrund bisheriger Erkenntnisse ist eine deutliche Anhebung des Einspritzdrucks auf 500 bar und mehr notwendig, um am Ottomotor Emissionsund Effizienzpotenziale heben zu können. Aber genau hier liegt auch die Krux des Themas. Eine massive Druckerhöhung geht auch mit erheblichen Kosten, technologischen Herausforderungen und einer Erhöhung der Reibungsverluste einher.

Ich gehe davon aus, dass aufgrund zukünftiger Herausforderungen der Einspritzdruck beim Ottomotor deutlich ansteigen wird. Diese Drucksteigerung wird nicht durch evolutionäre Anpassungen der aktuellen Seriensysteme erfolgen können, sondern wird neuartige Injektorkonzepte und Gesamtsysteme erfordern. 